\title{
TEACHING ENGLISH AS A FOREIGN LANGUAGE BY USING DIFFERENT TYPES OF TEXTS: THE GOALS
}

\author{
Zamira Abdujabbarova \\ Tashkent State Pedagogical University,Uzbekistan \\ zamirahon85@mail.ru
}

\begin{abstract}
Text plays an important role in teaching four basic language skills like reading, writing, listening and speaking. However, when using texts in the language classroom, skills should never be taught in isolation but in an integrated way. Teachers should try to teach basic language skills as an integral part of oral and written language use, as part of the means for creating both referential and interactional meaning, not merely as an aspect of the oral and written production of words, phrases and sentences.
\end{abstract}

Keywords: text and language skills, goals of text, types of text, text sets

\section{INTRODUCTION}

The processes of fundamental reforms in the Republic of Uzbekistan occurred in all spheres of social life including system of education.

"The main aims of all our reforms of economic policy are the individual. Therefore, the task of education, the task of rising up a new generation capable of national renaissance will remain the prerogative of the state and constitute a priority"

The law on "The Education System" and professional training programs implementation state priority of the Government policy, to impose public administration personnel, law protecting institutions and educational professionals, to establish necessary conditions for carrying out of the reforms on deepening the educational system. Of course, you all know that concern for the new generation, the need to bring up a sound, harmoniously developed person is a feature of our national character. Each person living on the holy land fights and works hard for all doing his best to bring up his children educated and goal natured, to see their happiness and prosperity.

This topic is bounded to the current system of education that is the theoretical basis of teaching different types of English texts is worth its implementation into practice. Needless to say, this way of teaching students is considered to the best contribution to our country's boom and prosperity in all spheres of life and society. 


\section{DISCUSSIONS}

\section{Texts in the process of teaching the Language Skills}

It is not easy to ascertain a teacher's role in a general or particular context because it is not static. It keeps on changing owing to the differences in syllabi, courses and teaching contexts. The ESP practitioner is a teacher first, so he must possess the qualities of a good general language teacher along with the specific qualities desired for his own field. 'The methodology of ESP teaching may not differ radically from that of General English'. An ESP teacher is not the 'primary knower' of the carrier content of the material. The reason is obvious because ESP includes the specific knowledge of the target situation, field of knowledge or profession but a teacher is, usually, trained in language skills only. That's why learners may know more about teaching material or content than teacher. A skilled teacher can analyze students' knowledge to bring forth effective communication strategies in the class. In certain ESP contexts, English for Academic Purposes (EAP), English for Occupational Purposes (EOP) and Business English, the teacher assumes the role of a mentor who offers one-to-one advice to students. This kind of special attention has proved to be more helpful to students in achieving their communication skills and 'linguistic accuracy. There are various teaching methods of text and the interpretations in teaching FL: Traditional, Direct, Bilingual, Activity Based Learning (ABL Method), Active learning method (ALM method), which are very essential in teaching process. They involve the learners into the process of education so that language develops automatically and spontaneously, where all the four language skills- listening, speaking, reading and writing - receive equal treatment.

Basic requirements for the text used in the educational process:

1) The cognitive/educational value of texts and their scientific aspects in contents: texts should include factual information about the country and people whose language is being studied, as well as intelligence from a variety of areas of human knowledge (popular science texts)

2) Ideological and educational value: the texts must not propagandize the cruelty and violence, should serve as a moral and ethical education of rules of conduct, be of educational value.

3) The content of the texts should be appropriate to the age and interests of the students. This content must be meaningful in the eyes of students of a particular age group, correspond to the level of their intellectual development and respond to their cognitive and emotional needs (John S. Hedgcock, Dana R. Ferris. 2009).

\section{Texts and Reading}

ESL / EFL teachers should adopt a dynamic, student-centered approach toward comprehension of a text. In reading lesson, discussion begins at the text level with direct questions of fact regarding main idea, details and suspicious queries which can be answered by specific reference to the text. When students master text understanding, they move to the inferential level, where they must make speculations and interpretations concerning the questions or statements following in the tasks, and where they produce the author's point of view. After 
comprehending a logical selection at the text and inferential levels, students are ready to do a collaborative work. That is to state that they share their evaluations of the work and their personal reactions to it - to its details, its theme, and the main point of view. This is also the suitable time for them to share their reactions to the work's natural cultural issues and themes. The third level, the personal/evaluative level stimulates students to think imaginatively about the text and provokes their problem-solving abilities.

Reading text is an interactive process that goes on between the reader and the text, resulting in comprehension. The text presents letters, words, sentences, and paragraphs that encode meaning. Reading is type of speech activity and the purpose of teaching at all stages. A person may read in order to gain information or verify existing knowledge, or in order to critique a writer's ideas or writing style. A person may also read for enjoyment, or to enhance knowledge of the language being read. The purpose(s) for reading guide the reader's selection of texts (Jalolov J., Makhkamova G., Ashurov Sh. 2015).

It is also important to give students interesting topics of life, traditions, and language realities of English-speaking countries. This goal of text can serve as disputable discussion among students while facing with their outlook, the use of which contributes to the essential requirements of the communicative method.

Moreover, the use of appropriate texts in the classroom contributes to individualization of learning and development of trainees' motivation speech. If you use texts on the foreign language lessons developed two types of motivation: self-motivation, when the material is interesting in itself, and motivation, which is achieved by the fact that the student will be shown that he can understand the language, which is studying (McKenna C, Michail, Robinson D, Richard. 2014).

\section{Texts and Writing}

Texts can be a powerful and motivating source for writing in ESL / EFL, both as a model and as subject matter. Text as a model occurs when student writing becomes closely similar to the original work or clearly imitates its content, theme, organization, and style. However, when student writing exhibits original thinking like interpretation or analysis, or when it emerges from, or is creatively stimulated by, the reading, texts serves as subject matter. Texts in immense variety of themes to write on in terms of guided, free, controlled and other types of writing.

\section{Texts with Speaking, and Listening}

The study of texts in a language class, though being mainly associated with reading and writing, can play an equally meaningful role in teaching both speaking and listening. Oral reading, dramatization, improvisation, role-playing, pandomiming, reenactment, discussion, and group activities may center on a work of text.

When we are talking about interaction of speaking, listening and text, we can say that it is already discourse.

Discourse is a use of written or spoken language in a social context. The study of discourse....can involve matters like context, background information or knowledge shared between a speaker and hearer (Bloor, Merial, and Thomos Bloor. 2013). 
It can be very short like "No smoking!", or "Stop.".

\section{Texts and Vocabulary}

Vocabulary occupies an important place in both native language and second/foreign language reading scholarship, since the words on the page are the starting point for reading. Thus, it is not surprising to see some emphasis on vocabulary in the ESP reading literature. Being related to semantic values and area specific context, technical terminology is one of the factors distinguishing EVP from EGP. In the beginning, teachers often thought that in ESP courses, teaching specific vocabulary was their task. However, in many situations adult professionals know the technical terms related to their field much better than the teacher, who often does not know the field-specific terminology. A typical two or three - hour a week ESP course would not have the time or space necessary to teach all of the specialized vocabulary students would need to learn and that teaching of a pre - determined word - stock is unnatural. To account for this situation, we can say five vocabulary learning strategies suitable for ESP: "(1) inferring from context, (2) identifying lexical familiarization, (3) unchaining nominal compounds, (4) synonym search and (5) word analysis" (McKenna C, Michael, Richard D. Robinson, 2014). For determination of the text language comprehension we should keep in mind its lexical and grammatical features.

Evaluating lexical difficulty of the text it is necessary to be considered the number of unknown lexical units and the number of newly learned vocabulary by the time of reading this text, as well as the role of unknown words which is carried out in the transfer of semantic information. Evaluating grammatical difficulty of text it is considered the ration of simple and complex sentences, the presence of structures which don't have analogues in native language. Unknown grammatical forms in educational texts for reading are not included, but if they are, they always should be explained in the footnotes.

Depending on the location of the new words and their number, the text is used for the development of different types of reading. If new words are associated with the transmission of the basic information, the text is recommended for the development of methods of Intensive Reading. If their number is small (one or two per page), the text can be used for skimming reading, if more than ten or twelve per page (4-6\%), it is advisable to use intensive reading. If the text contains more words, it is generally not suitable for learning to read. As its understanding is the result of decoding the text, rather than reading. If new words are means of transmitting secondary information, this text used to develop techniques of scanning reading. Such texts are best suited for skimming reading, if the total number of unfamiliar words not more than ten or twelve per page $\left(\mathrm{O}^{\prime}\right.$ Malley. J.M \& Chamot. A.D.1995).

Developing the idea of the role of reading in the learning process, G.V. Rogova emphasizes, 'the process of reading, involving analysis, synthesis, generalization, inference and prediction carries a significant educative and breeding role. 'It is often difficult to convince students of English as a foreign language that texts in English can be understood even though there are vocabulary items and structures that the students have never seen before. Skills such as extracting specific information can be satisfactorily performed even though the students do not understand the whole text; the same is true for students who want 
to 'get the general idea' of a text .It is consider vitally important to train students in these skills since they may well have to comprehend reading in just such a situation in real life ( Rogova G.V.1975).

Teaching reading is challenging because there is so much knowledge that we have gained over the decades and knowing how to use this knowledge becomes critical. Text-work is an awfully convenient way of filling up a language lesson, and teachers often feel that any text-based activity is bound to be beneficial. This is not necessarily the case.

In years past, an oversimplified approach was sometimes taken to reading instruction. Teachers usually had a single book that they used for most or even all their students. Sometimes teachers grouped students and had different students reading in different levels of books. However, as we have gained new knowledge it has become much clearer that in order to meet the varying needs of students as they learn to read, we need a variety of types of texts.

Texts types are species that take place in literature and writings that have literary value. Texts take place in Uzbek Subject curriculum and textbooks prepared in accordance with this curriculum were classified as poetry, informative and narrative texts. Informative text is the text of which function is to submit information and messages can be used in real life situation and be actualized. Narrative texts are life quality texts that, improves life more than knowledge. Both the narrative and descriptive text has a hierarchical structure. There are definitions, rank, ranking, cause-effect relationships, problem/solution, and comparison among the basic structural patterns. Informative text is written to give readers new information. Teaching and understanding informative texts are more difficult than narrative texts because of their structure. Informative texts deal with more abstract concepts in the respect of subject.

The use of different types of texts is most significant at the beginning levels of reading. There are six distinctly different types of texts that can be used for reading instruction: wordless books; predictable texts; controlled high-frequency vocabulary texts; decodable texts; authentic literature; and created, easy-to-read texts.

\section{Wordless Books}

Wordless books are a part of the category of children's literature identified as picture books. These are books that tell their story or present information through illustrations or photographs without printed words on the page. Students at the early stages of literacy development can use these books as ways to develop vocabulary, oral language, and self-expression. Wordless books can be used effectively:

a. During beginning reading to develop oral language, vocabulary, concept of story, and concept of books.

b. For second language learners as they develop their foundation for English reading.

c. For older students in the elementary and middle school levels who need to develop a better understanding of being a reader or for those who need foundational skills.

d. For students at all levels, wordless books can serve as a stimulus for writing. 


\section{Predictable Texts}

Predictable texts are ones that have a repeated pattern of some type. Seven patterns of predictability in texts:

1. Phrase or sentence repeated

2. Repetitive-cumulative pattern in which a word, phrase, or sentence is repeated.

3. Rhyming Patterns.

4. Familiar cultural sequences, cardinal and ordinal numbers.

5. Familiar cultural sequences, alphabet.

6. Familiar cultural sequence, days, months, colors.

7. Predictable plots.

Predictable books along with shared reading are often recommended as a way to introduce beginning learners to the feeling of being a reader. Predictable texts help children very quickly come to think of themselves as readers. Often the children memorize the text and can repeat the text without even looking at it. In this way, children think of themselves as readers and have fun reading.

\section{Decodable Texts}

Decodable texts are ones that contain a high number of words that use the sound-letter relationships that children are being taught as well as a limited number of high-frequency words. These texts may also include a limited number of "special words" or "story words." For example, if students know the lettersound relationships for $m / \mathrm{m} /, s / s /, t / t /, p / p /$, e lel, and $a / a /$ and the highfrequency and special words the, elephant, said, no, and thank you, they can read the following story: Pat and the Elephant.

The benefit of this type of text is that it allows students to practice sequential decoding and develop fluency and automaticity, critical parts of beginning reading instruction. We can say decodable text is linguistically controlled text. Selecting decodable texts carefully is very important. There are offered four guidelines for this process in a beginning reading program:

1. Stories that have a significant proportion of decodable words.

2. A sequence of stories, such that the sound letter relations the children have learned are cumulatively reviewed in the words of the stories.

3. Stories those are comprehensible.

4. Words in the stories that are in the children's spoken vocabularies.

\section{Controlled High-Frequency Vocabulary Texts}

Controlled high-frequency vocabulary texts were associated with beginning reading instruction. Using controlled high-frequency vocabulary texts provides learners practice in recognizing those words that make up a very high proportion of the words found in beginning reading materials. Just over 100 words account for about half of the running words in texts through third grade. Knowing this important core of words should help children read not only texts being used for reading instruction, but other beginning reading texts as well. High - frequency words can be carefully introduced and practiced in decodable text. 


\section{Authentic Literature}

Authentic literature consists of narrative and expository texts in the original form as written by the author. Similarly, an authentic text would be a text "normally used in the students' specialist subject area: written by specialists for specialists". No editorial attempts are made to make these texts easier by rewriting them to conform to readability guidelines or given vocabulary lists. Authentic literature comes in the form of books, anthology selections, magazines, newspapers, and others. Authentic literature is motivating for students. It captivates their attention and engages them in learning. Authentic literature provides students with natural language texts that continually help them develop and expand their own language structures. Real literature is generally easy for most students to understand.

\section{Created, Easy-to-Read Texts}

Created, easy-to-read texts are ones that are written for students beyond the beginning level of reading to apply various skills and strategies in text below their age-appropriate level of difficulty. These texts provide students who are reading below level the opportunity to practice and apply skills and strategies they are being taught in texts that they can read. For students who are progressing normally, these texts provide them a chance to practice and apply a particularly difficult strategy or skill in text below their level and continue to practice reading and develop fluency. These texts, like decodable texts, serve as stepping stones to get students into authentic literature (Cooper, J. David. 2001).

\section{Non-fiction texts}

Non-fiction texts are factual texts with content that is generally expected to be true. They include reports, factual recounts, instructions, explanations, persuasions and arguments. Non-fiction texts contain specific information or ideas; their primary purpose is to convey information about both our physical world and our social world. They are usually written in the third person. Factual recounts are written about things that have happened; they are usually written in the past tense and, while they may include description, this is factual. Instruction texts provide guidance on how to do something, telling you what is needed, what to do (through the use of verbs) and the order in which something should be done. Explanations explain things - telling the reader what, how and why about a subject, an issue or phenomena, and are written in the present tense. Persuasive texts try to convince the reader to agree with something or someone, or to do something, and often contain a mix of fact and opinion and persuasive and emotive language.

\section{Professional texts}

Over the years, there has been a growing interest for non-fiction genres, both in relation to genres that appear in the public media and what is here referred to as professional texts. Professional texts are an (extremely broad) sub-category of non-fiction; they may share many of the characteristics of non-fiction texts in general, but a number of following requirements must be met in order to classify a text as a professional:

1. The communication takes place in a professional or academic context; 
2. The communicative purpose is professional;

3. At least one of the communicating parties has professional or specialist knowledge;

4. The subject matter is of a professional nature (Şahin, Ayfer. 2013).

\section{Text Sets}

"A text set collection focuses on one concept or topic and can include multiple genres such as books, charts and maps, informational pamphlets, poetry and songs, photographs, nonfiction books, almanacs, or encyclopedias"

Suggested that text sets support an inquiry model of learning that will do the following:

a. Lead to inter textual connections.

b. Cause students to confront multiple perspectives.

c. Provide visual elements, which reinforce and deepen concept understandings.

d. Reinforce the interrelatedness of reading, writing, speaking, listening, and thinking.

e. Provide avenues for authentic assessment and evaluation (Teaching through texts sets. 2013).

\section{Literary texts in teaching FL}

The role of literature is a basic component and source of authentic texts of the language curriculum. Many teachers consider the use of literature in language teaching as an interesting and worthy concern. The use of literature as a technique for teaching both basic language skills (i.e. reading, writing, listening and speaking) and language areas (i.e. vocabulary, grammar and pronunciation) is very popular within the field of foreign language learning and teaching nowadays. Moreover, in translation courses, many language teachers make their students translate literary texts like drama, poetry and short stories into the mother tongue, Uzbek.

In the following section, why language teachers use literary texts in the foreign language classroom and main criteria for selecting suitable literary texts in foreign language classes are stressed so as to make the reader familiar with the underlying reasons and criteria for language teachers' using and selecting literary texts.

\section{Reasons for Using Literary Texts in TFL}

There are four main reasons which lead a language teacher to use literature in the classroom. These are valuable authentic material, cultural enrichment, language enrichment and personal involvement. In addition to these four main reasons, universality, non-triviality, personal relevance, variety, interest, economy and suggestive power and ambiguity are some other factors requiring the use of literature as a powerful resource in the classroom context. 


\section{Valuable Authentic Material}

Literature is authentic material. Most works of literature are not created for the primary purpose of teaching a language. Many authentic samples of language in real-life contexts (i.e. travel timetables, city plans, forms, cartoons, advertisements, newspaper or magazine articles) are included within recently developed course materials. Thus, in a classroom context, learners are exposed to actual language samples of real life / real life like settings. Literature can act as a beneficial complement to such materials, particularly when the first "survival" level has been passed. In reading literary texts, because students have also to cope with language intended for native speakers, they become familiar with many different linguistic forms, communicative functions and meanings.

\section{Cultural Enrichment}

For many language learners, the ideal way to increase their understanding of verbal / nonverbal aspects of communication in the country within which that language is spoken - a visit or an extended stay - is just not probable. For such learners, literary works, such as novels, plays, short stories, etc. facilitate understanding how communication takes place in that country. Though the world of a novel, play, or short story is an imaginary one, it presents a full and colorful setting in which characters from many social / regional backgrounds can be described. A reader can discover the way the characters in such literary works see the world outside (i.e. their thoughts, feelings, customs, traditions, possessions; what they buy, believe in, fear, enjoy; how they speak and behave in different settings. Literature is perhaps best regarded as a complement to other materials used to develop the foreign learner's understanding into the country whose language is being learned. Also, literature adds a lot to the cultural grammar of the learners.

\section{Language Enrichment}

Literature provides learners with a wide range of individual lexical or syntactic items. Students become familiar with many features of the written language, reading a substantial and contextualized body of text. They learn about the syntax and discourse functions of sentences, the variety of possible structures, and the different ways of connecting ideas, which develop and enrich their own writing skills. Students also become more productive and adventurous when they begin to perceive the richness and diversity of the language they are trying to learn and begin to make use of some of that potential themselves. Thus, they improve their communicative and cultural competence in the authentic richness, naturalness of the authentic texts.

\section{Personal Involvement}

Literature can be useful in the language learning process owing to the personal involvement it fosters in the reader. Once the student reads a literary text, he or she begins to inhabit the text. The student becomes enthusiastic to find out what happens as events unfold via the climax; he/she feels close to certain characters and shares their emotional responses which can have beneficial effects upon the learning process. The prominence of the selection of a literary text in relation to the needs, expectations, and interests, language level of the students is 
evident. In this process, he/she can remove the identity crisis and develop into an extrovert. There are the lists of the reasons for regarding literature as a potent resource in the language classroom as follows:

1. Universality

2. Non-triviality

3. Personal Relevance

4. Variety

5. Interest

6. Economy and Suggestive Power

7. Ambiguity

When selecting the literary texts to be used in language classes, the language teacher should take into account needs, motivation, interests, cultural background and language level of the students. However, one major factor to take into account is whether a particular work is able to reveal the kind of personal involvement by arousing the learners' interest and eliciting strong, positive reactions from them. Reading a literary text is more likely to have a long-term and valuable effect upon the learners' linguistic and extra linguistic knowledge when it is meaningful and amusing. Choosing books relevant to the real-life experiences, emotions, or dreams of the learner is of great importance. If the language of the literary work is simple, this may facilitate the comprehensibility of the literary text but is not in itself the most crucial criterion. (Hişmanoğlu, Murat. 2005).

Enjoyment; a fresh insight into issues felt to be related to the heart of people's concerns; the pleasure of encountering one's own thoughts or situations exemplified clearly in a work of art; the other, equal pleasure of noticing those same thoughts, feelings, emotions, or situations presented by a completely new perspective: all these are motives helping learners to cope with the linguistic obstacles that might be considered too great in less involving material.

\section{CONCLUSION}

To conclude, we can say that texts can revolutionize the field of education. In fact, with the onset of them in FLT, it becomes easier for teachers to impart knowledge and for students to acquire it which is the main aim of my investigation. Being a part of the curriculum the texts ought to render not just knowledge, but world outlook and be a source for other three communicative language skills. As we live in the world with skyrocketing development, highly qualified and competitive specialists are apparently in a need. So, the ultimate goal of vocational education should be the professionals who are capable of contributing to the advancement of the field in which they work. Different types of texts make learning efficient, stimulate self-activity, help in overcoming difficulties, develop greater understanding, foster critical thinking, and bring the world of professions into the classroom.

\section{REFERENCES:}

Bloor, Merial, and Thomos Bloor. (2013). Practice of critical discourse Analysis: An introduction. Routledge.

Conference. (2013). Teaching through texts sets. Research-based Curriculum. $C A$ : Teacher created materials publishing. $6 \mathrm{p}$. 
Cooper, J.David. (2001). Using Different Types of Texts for Effective Reading Instruction. Houghton Mifflin Company. 11p.

Jalolov J., Makhkamova G., Ashurov Sh. (2015). English language teaching methodology. Tashkent. $336 \mathrm{~b}$.

John S. Hedgcock, Dana R. Ferris. (2009). Teaching Readers of English Students, Texts, and Contexts. -NY: Routledge, Taylor and Francis. 452p.

Hişmanoğlu, Murat. (2005). Teaching English through Literature. Journal of Language and Linguistic Studies. 54-66.

McKenna C, Michail, Robinson D, Richard. (2014). Teaching through Text: Reading and Writing in the content Areas, 2nd Edition- Pearson: University of Missouri-Columbia press. 288p.

O' Malley. J.M \& Chamot. A.D. (1995). Learning strategies in second language acquisition,-Cambridge: Cambridge University Press. 605 p.

Rogova G.V. (1975). Methods of teaching English. Moscow. 312p.

Şahin,Ayfer. (2013). The Effect of Text Types on Reading Comprehension. Mevlana International Journal of Education. 57-67pp. 